\title{
Aterrando no sul: uma proposta político-epistemológica para a área de educação em ciências do Antropoceno
}

\section{Landing in the South: a political-epistemological proposal for the area of science education in the Anthropocene}

Nathan Willig Lima

Matheus Monteiro Nascimento

Universidade Federal do Rio Grande do Sul (UFRG), Instituto de Física, Bento Gonçalves, RS, Brasil. Autor correspondente: nathan.lima@ufrgs.br

Resumo: A disseminação da COVID-19, a mutação climática, o aumento das desigualdades sociais e o avanço da necropolítica, bem como a negação desses elementos por parte da população mundial e brasileira, exigem um novo mapa dos posicionamentos políticos e epistemológicos. Dialogando com a epistemologia política de Bruno Latour e com as Epistemologias do Sul, apresentamos uma reflexão sobre como a área de Educação em Ciências pode se articular para dar conta das questões que se impõem na contemporaneidade. Defendemos, nesse trabalho, concordando com Latour, que a Educação em Ciências precisa 'aterrar' e que, para isso, é necessário se aliar diplomaticamente aos atores do antigo eixo 'absolutista / relativista'. Diferentemente de Bruno Latour, entretanto, defendemos que o protagonista no Antropoceno não será mais a Europa, mas o Sul político e epistemológico do mundo, e a educação em ciências brasileira pode ter papel crucial nesse movimento.

Palavras-chave: Epistemologia; Antropoceno; Filosofia política; Filosofia das ciências.

Abstract: The spread of COVID-19, climate change, the increase in social inequalities, and necropolitics, as well as the denial of these elements by the world and the Brazilian population, require a new definition of political and epistemological positions. In dialogue with Bruno Latour's political epistemology and with Epistemologies of the South, we present a reflection on how Science Education can articulate itself to deal with the issues that are imposed in contemporary times. In this paper, agreeing with Latour, we contend that Science Education needs to 'land', and that it is necessary to ally diplomatically with the actors of the old 'absolutist / relativist' axis. Unlike Bruno Latour, however, we argue that the protagonist in the Anthropocene will no longer be Europe, but the political and epistemological South of the world, and Brazilian science education may play a crucial role in this movement.

Keywords: Epistemology; Anthropocene; Political philosophy; Philosophy of sciences.

Recebido em: 13/12/2020

Aprovado em: 30/05/2021 


\section{Introdução}

Em 2020, mais de cento e oitenta mil brasileiros e mais de um milhão e quinhentas mil pessoas no mundo perderam a vida por complicações causadas pela COVID-19¹. Como diz o filósofo e historiador Achille Mbembe (MBEMBE, 2020), o mundo se tornou irrespirável. Apesar de ser um drama global, a pandemia, seus efeitos sanitários e econômicos afetam distintamente os diferentes grupos sociais (SANTOS, 2020), o que é corroborado por estudos empíricos no contexto internacional (CÉNAT et al., 2020) e brasileiro (RODRIGUES et al., 2020). A propósito, independentemente do vírus, sabe-se que são grupos específicos que morrem sem ar - como denuncia o movimento I can't breathe nos Estados Unidos (COSTA, 2020).

Se, por um lado, 2020 nos apresentou a um mundo sem ar, para muitos, há muito tempo, vivemos em um mundo sem terras: a questão da imigração na Europa tensionou a saída do Reino Unido da União Europeia, os Estados Unidos construíram um muro na fronteira com o México para evitar a imigração de latinos, e brasileiros expulsaram venezuelanos cantando o hino nacional. Embora esses fatos sejam relativamente recentes, a questão colonial, no mundo, e a organização do espaço terrestre e sua (não) democratização, no Brasil, é uma questão histórica, como discute Lélia Gonzalez (GONZALEZ, 1982).

Além das questões da desigualdade social e da falta de terra e ar, o cenário contemporâneo é marcado por uma ascensão de movimentos anti-ciência e pela formação do que se pode entender por período de pós-verdade (LIMA et al., 2019), envolvendo, entre outros elementos, a negação do aquecimento global antropogênico e de todas as consequências advindas de seu reconhecimento. Os movimentos negacionistas, entretanto, apesar de suscitarem questões relevantes com relação à natureza do conhecimento e dos critérios de demarcação, não podem ser entendidos à luz de uma discussão puramente epistemológica. O problema é, ao mesmo tempo, epistemológico e político.

Em seu último livro, Onde aterrar?: como se posicionar politicamente no Antropoceno, o filósofo e antropólogo francês Bruno Latour (LATOUR, 2020a) defende a tese de que os problemas supracitados são diferentes dimensões do mesmo fenômeno. Para defender sua tese, Latour apresenta uma discussão pautada em suas construções teóricas anteriores e em episódios históricos recentes, como a eleição de Donald Trump em 2016. Sua análise indica que a organização política entre direita e esquerda não é mais suficiente para explicar a complexidade política e epistêmica do mundo.

Nosso objetivo, neste trabalho, é apresentar uma análise da tese de Latour (2020a) à luz de suas obras anteriores, explicitando seus compromissos metafísicos, epistemológicos e políticos. Apesar de concordar com Latour com relação ao fato de que devemos "aterrar", apresentamos uma reflexão discordando do autor, com relação ao que ele afirma sobre o território europeu ser o palco da construção de soluções para o Antropoceno. Defendemos que, para construirmos soluções efetivas, será necessário aterrar no Sul, territorial, político e epistemológico.

A partir de tal discussão, traçamos reflexões para área de educação em ciências. Em especial, propomos que o eixo 'absolutista / relativista', comum na área de educação 
em ciências ao tratar de posicionamentos epistemológicos, não é suficiente para pensarmos sobre a educação científica contemporânea. Se quisermos conceber a área de Educação em Ciências de forma que ela consiga, de fato, dialogar com os dilemas do mundo contemporâneo, precisamos de um novo esquema político-epistemológico também no campo científico-pedagógico. Inspirados na proposta de Latour (2020a) e nas Epistemologias do Sul (SANTOS, 2019), propomos que a educação em ciências deve 'aterrar' e ela deve 'aterrar no sul'. Discutimos, também, implicações práticas de tal proposta.

\section{De Jamais fomos modernos a Onde aterrar: a epistemologia política de Bruno Latour}

Bruno Latour, filósofo e antropólogo francês, ficou conhecido pelo seu polêmico trabalho, escrito originalmente em 1979, A vida de laboratório: a produção dos fatos científicos (LATOUR; WOOLGAR, 1997), no qual o nascimento de um novo fato científico é narrado sob um ponto de vista antropológico, inaugurando o que alguns chamam de Antropologia do Laboratório (COLLINS; EVANS, 2002). Acusado de relativista e antirealista (BUNGE, 1999; SOKAL; BRICMONT, 2010), Latour protagonizou o que ficou conhecido como Guerras nas Ciências (Science wars), sendo considerado por muitos um inimigo das ciências.

Muito das polêmicas em torno de suas ideias se deve, talvez, a afirmações, de fato, contundentes e arrojadas realizadas pelo autor. Por outro lado, quando essas afirmações são interpretadas e entendidas à luz do quadro teórico mobilizado por ele, encontra-se, no pensamento de Latour, uma potente lente teórica para entender as ciências, suas práticas e suas relações com a sociedade, para além da dicotomia do absolutismo/relativismo epistemológico (LIMA et al., 2019), principalmente ao que se refere, mais recentemente, à mutação climática (COSTA, 2017). Ademais, as ideias de Bruno Latour têm sido bastante exploradas em diferentes estudos da área de Educação em Ciências (COUTINHO; SILVA, 2016; DRESSLER; SILVA; SATO, 2020; FARIA; COUTINHO, 2015). Nesta seção, apresentamos uma visão geral de alguns elementos da filosofia de Latour, principalmente optando por aqueles que nos permitem interpretar o seu último livro (LATOUR, 2020a), o qual pretendemos discutir em maior profundidade.

Como aponta Alyne Costa (COSTA, 2020), no posfácio do livro supracitado, a última obra de Latour guarda uma grande semelhança com seu ensaio de antropologia simétrica, Jamais fomos modernos (LATOUR, 2013), publicado originalmente em francês em 1991, uma vez que ambos apresentam possibilidades para que o leitor possa se posicionar no tempo em que está vivendo. Em especial, o livro foi escrito após a queda do Muro de Berlim e, após as primeiras conferências sobre a mudança de regime climático, dois acontecimentos que marcam, segundo Latour (2013), o fim dos ideais modernistas. Em sua discussão, o autor argumenta que o pensamento modernista reside sobre uma suposta separação entre dois polos ontológicos distintos e irreconciliáveis, a natureza e a sociedade.

Tal quadro ontológico cria uma dicotomia, cujas consequências se arrastam por toda constituição do pensamento moderno. A natureza, independente da organização social, é composta por objetos (no sentido de serem livres de qualquer subjetividade), enquanto os homens estão eternamente presos em suas subjetividades, em sua irracionalidade e suas emoções. 
As consequências políticas dessa visão ficam claras em Políticas da natureza: como fazer ciência na democracia, no qual Latour (2004a) explica tal constituição e suas implicações, por meio do mito da caverna. Para Platão, estamos eternamente presos em nossa caverna de subjetividade, enquanto as verdades, puras, absolutas, objetivas e independentes do homem, pairam cintilantes fora da caverna. Esse mito, apesar de parecer ingênuo, traz consequências políticas sérias: cria-se a figura do sábio, esse ator capaz de sair da caverna, ver as verdades e voltar para contar aos homens. Cabe aos homens da caverna nada senão aceitar a verdade que o sábio viu. Séculos depois, o mito platônico ainda organiza a vida social quando se mobiliza o argumento científico para fazer calar a população. A busca por um governo técnico, a ojeriza à política, o argumento de autoridade do cientificamente comprovado, são os artifícios resultantes dessa constituição modernista. A Ciência (com C maiúsculo, absoluta, certa, infalível) aprisionou a política (entendida, no contrato modernista, como uma prática dos prisioneiros da caverna social) e fez calar qualquer possibilidade de democracia.

Essa visão de Natureza, como uma composição de objetos inertes e objetivos, teve profunda contribuição do pensamento cartesiano e sua divisão do res extensa e res cogitans e de Kant com a separação dos objetos em si e o ego transcendental (LATOUR, 2017). Mais recentemente, Latour (2020b) discute, também, a contribuição da obra galileana para tal concepção. Visão semelhante aparece, também, na obra de Hanna Arendt (ARENDT, 2007). De acordo com essa visão, o uso do telescópio por Galileu fez a Terra se tornar um objeto como qualquer outro no meio do espaço, unificando o mundo infra e supralunar. Passamos a olhar para a Natureza a partir de um ponto de vista sideral, distante, observando apenas um aglomerado de corpos em queda livre. Nesse sentido, Latour argumenta que a noção de Natureza (com N maiúsculo) como uma instituição pronta, definida, objetiva e independente é incompatível com a democracia. $E$, na verdade, também é incompatível com a própria ciência (com c minúsculo, ciência encontrada nos laboratórios, nas missões de campo, nos gabinetes), que a sociologia e a antropologia da ciência vêm há décadas analisando e descrevendo.

Assim, Latour (2004a) identifica que o movimento ecológico, ao buscar proteger a Natureza, nada fez senão sustentar e fortalecer o contrato modernista, uma vez que busca, nessa instituição, as Verdades que calam a política. Tal prática, entretanto, além de incompatível com a descrição da ciência feita por sociólogos e antropólogos, tem se mostrado ela mesma infértil no sentido de articular e mobilizar redes em direção a um outro coletivo. Para que possamos entender os problemas ecológicos e mobilizar atores em busca de soluções urgentes, Latour (2004a) argumenta, precisamos abandonar o contrato modernista e, com isso, a noção de uma Natureza singular e absoluta. Precisamos reconhecer não somente um multiculturalismo, mas um 'multinaturalismo'.

A tarefa não é fácil e exige reconstituir uma nova cosmovisão, afastando-se da ontologia, da epistemologia, da sociologia e da política modernistas (LATOUR, 2017). Em Esperança de Pandora: ensaios sobre a realidade dos estudos das ciências, Latour (2017) apresenta sua concepção metafísica, baseada principalmente, mas não somente, na metafísica processual de Alfred Whitehead (WHITEHEAD, 1978). Segundo essa visão, a existência de qualquer ator (chamado por Whitehead de proposição) depende de suas relações com outros atores. A existência, nesse sentido, é uma propriedade não binária e relacional. Para uma discussão detalhada da concepção metafísica de Latour, 
sugerimos a obra de Harman (2009) e para um panorama da visão metafísica de Latour e suas implicações para educação em ciências, sugerimos o trabalho de Lima et al. (2019).

Na proposição de Latour, ademais, não se faz distinção, a priori, entre o objetivo e o subjetivo, mas, simplesmente, entre humanos e não humanos. Em especial, os atores da contemporaneidade, que desempenham papel fundamental nos problemas ecológicos, são híbridos de natureza e sociedade e jamais poderiam ser entendidos completamente com a visão objetivista. Buracos na camada de ozônio são, ao mesmo tempo, naturais, sociais e discursivos (LATOUR, 2013).

Tal concepção metafísica funde, de uma só vez, as áreas filosóficas que o contato modernista separou (ontologia, epistemologia, sociologia e política). Não existe mais a Natureza (objetiva), tão pouco a Política puramente social. Existem coletivos de natureza-sociedade que se encontram, disputam e viabilizam (ou não) a construção de um mundo e de um senso comum (STENGERS, 2020). Inspirado no pensamento de Isabelle Stengers, Latour (2017) adota a concepção de uma 'cosmopolítica', isto é, o processo da construção do mundo comum (universo) a partir dos diferentes coletivos natureza-sociedade, ou diferentes proposições (pluriverso).

É com essa concepção cosmopolítica que Latour (2005) diferencia epistemologia (política) e epistemologia política. A epistemologia (política) refere-se ao processo de instituição da Ciência absoluta, descobridora da Natureza. Tal narrativa não é sustentável pela observação da prática científica e, portanto, a Ciência (absoluta) só é possível de ser institucionalizada por uma prática política, forçosa, anti-democrática. Por outro lado, o trabalho da epistemologia política é liberar as ciências da concepção política que a epistemologia (política) Ihe incumbiu. Não havendo mais Natureza, as ciências estão livres para articular proposições, construir híbridos, disputar a construção de um mundo comum. A epistemologia política trata de descrever os processos de associações entre os diferentes atores humanos e não humanos em sua cosmopolítica. Faz-se, ao mesmo tempo, uma sociologia dos humanos e não humanos, uma vez que sociologia passa a ser o estudo das associações e não das relações humanas somente (LATOUR, 2005).

Em especial, de vital importância para nossa discussão, esse novo quadro metafísico permite repensar as questões ecológicas que se apresentam diante de nós. Em Diante de Gaia: oito conferências sobre a natureza no antropoceno, Latour (2020b) discute, entre outros tópicos, a importância da teoria Gaia e da definição de Antropoceno. Primeiramente, a teoria Gaia, proposta por James Lovelock, é, segundo Latour, uma anti-revolução galileana. Se Galileu, com seu telescópio, mostrou que a Terra era uma rocha no espaço vazio, como qualquer outro corpo, Lovelock, com um experimento mental, mostrou que a Terra é única e totalmente diferente de tudo que observamos no espaço. Em especial, o que acontece debaixo da atmosfera terrestre indica haver uma articulação entre os diferentes atores terrestres, afetando e sendo afetados por Gaia. Não é possível pensar em um conjunto de seres vivos transitando por um cenário inerte. O cenário também é um ator abaixo da atmosfera terrestre. Lovelock restitui a quebra entre mundo supra e infra lunar (agora como mundo supra e infra atmosférico). 
Não somente isso, mas os geólogos têm indicado que a ação de povos humanos tem sido tão intensa que foi capaz de mudar a própria constituição geológica da Terra (LATOUR, 2020b). Saímos do Holoceno, período de extrema estabilidade geológica, em que toda civilização se constituiu, e entramos em um novo período. Como diria Latour, nem o maior dos construtivistas sociais ousaria dizer que além da desigualdade de gênero, das desigualdades sociais e do racismo, também são construídas pelo homem a composição da atmosfera terrestre, a movimentação das correntes marítimas, a temperatura do planeta. Mais do que nunca, a concepção de uma cosmopolítica faz sentido. Humanos e não humanos disputam a construção do mundo comum, afetando e sendo afetados, transformando e sendo transformados uns pelos outros. A natureza não está pronta para ser descoberta nem a sociedade está presa em sua caverna. Naturezas e sociedades são o que estamos construindo, os produtos da cosmopolítica. Deve-se ressaltar que, apesar de falar de 'humanos', Latour (2020b) ressalta que não se pode pensar na humanidade como uma instituição única, mas um conjunto de diferentes povos com diferentes responsabilidades e compromissos no caminho que está sendo encaminhado para o Antropoceno:

É por isso que o Antropoceno, apesar do nome, não é uma extensão imoderada do antropocentrismo, como se pudéssemos sentir orgulho de termos sido transformados para sempre em uma espécie de Super-Homem voador em traje vermelho e azul. Pelo contrário, é o humano como um agente unificado, como uma simples entidade política virtual, como um conceito universal, que deve ser dividido em vários povos distintos, dotados de interesses contraditórios, de territórios em luta, e convocados sob os auspícios de entidades em guerra - para não dizer divindades em guerra. O Anthropos do Antropoceno? É Babel após a queda da torre gigante. Finalmente, os humanos não são mais unificáveis! Finalmente, não estão mais fora do solo! Finalmente, não existe mais um fora da história terrestre! (LATOUR, 2020b, p. 197).

Essa breve discussão nos permite chegar no ponto em que Latour (2020a) inicia seu relato em Onde aterrar: como se posicionar politicamente no antropoceno. Se Jamais fomos modernos foi escrito após a queda do muro de Berlim, Onde aterrar começou a ser escrito após a eleição de Donald Trump para presidência dos Estados Unidos, em 2016. Latour apresenta, em seu livro, em uma linguagem bastante coloquial, aquilo que ele chama de uma hipótese de ficção política, que é a ideia de que três fenômenos, aparentemente distintos, - a desregulamentação após a queda do muro de Berlim, a mutação climática e a explosão recente das desigualdades sociais - são, na verdade, um único e mesmo fenômeno. Para explicar tal proposição, Latour parte do esquema político tradicional e avança para a proposição de um novo mapa político.

De acordo com o esquema tradicional, pode-se dividir os posicionamentos políticos em dois grandes grupos: direita e esquerda. Para Latour (2020a), esses dois posicionamentos antagonizam em diferentes questões em relação à busca do global ou do local. A busca do global, em certa medida, resgata a noção da busca da modernidade e a superação de um passado 'bárbaro' enquanto a defesa do local pode ser entendida como o que há para ser modernizado. Deve-se ter clareza, entretanto, que não se trata de indicar que a direita busca o global e a esquerda o local ou vice-versa. Os posicionamentos se alternam dependendo da questão. A direita, por exemplo, ao defender a desregulamentação do mercado a ponta para o global, enquanto a esquerda, 
por outro lado, na questão dos costumes, defende uma visão global, se opondo à visão retrógrada das tradições. O esquema político pode, portanto, ser representado graficamente como apresentamos na Figura 1 (A).

Figura 1 - Representação gráfica do esquema político
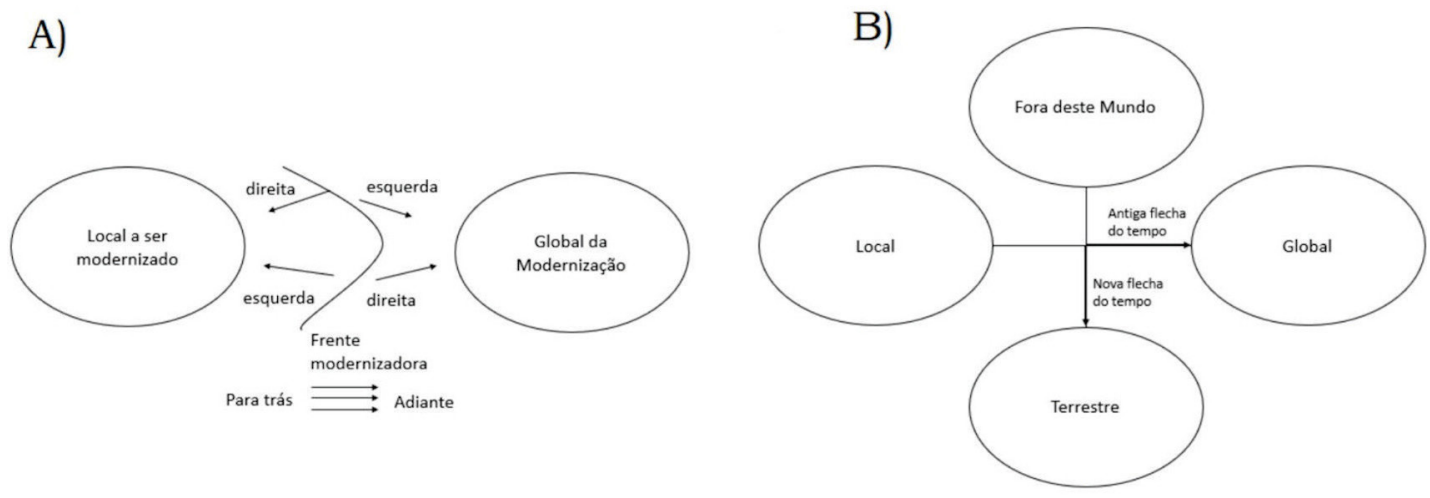

(A) Esquema tradicional sobre posicionamento políticos e sua relação com a noção de modernidade;

(B) Novo mapa político proposto por Latour.

Fonte: adaptado de Latour (2020a).

O global e o local, nesse sentido, podem ser pensados como 'atratores' que organizam a discussão política e a ordem social. Conforme Latour (2020a) aponta, entretanto, o termo globalização é usado no vocabulário para designar dois processos distintos. O primeiro, chamado por Latour de 'global mais', é definido pelo autor como "[...] uma multiplicação dos pontos de vista, o registro de um número maior de variedades, a consideração de um maior número de seres, de culturas, de fenômenos, de organismos e de pessoas" (LATOUR, 2020a, p. 22). Apesar disso, o que se tem percebido e entendido por globalização, recentemente, aponta justamente na direção contrária, sendo definida como 'globalização menos', isto é, a imposição a todos, de uma única visão provinciana, e o atendimento do interesse de poucos.

A hipótese inicial de Latour (2020a) pode então ser explicada: desde os primeiros resultados sobre a mutação climática, as elites do mundo foram avisadas sobre a necessidade de uma mudança significativa na organização social e econômica, uma vez que não há recursos suficientes para que todo o mundo compartilhe do padrão de consumo dos países colonizadores. Ao invés de seguir o ideal da construção de um mundo global comum (no sentido da globalização mais), essas elites decidiram abdicar da construção de um mundo comum e construir um mundo apenas para si. Isso explica a desregulamentação do mercado e o desmantelamento do Estadoprovidência, causando a explosão de desigualdades sociais. Em síntese, as 'elites obscurantistas' decidiram, diante da mutação climática, negá-la sumariamente em seu discurso, forjando a ideia de que um mundo global ainda seria possível, mas decidindo construir um mundo só para si, e relegar o resto do mundo à miséria.

Ademais, em paralelo com essa distinção entre globalização-mais e globalizaçãomenos, é possível propor as noções de um local-mais - entendido como um conjunto de sentimentos legítimos sobre a preservação de costumes e práticas locais - e um local-menos, resultado da globalização-menos, que envolve a defesa de uma "[...] tradição, a proteção, a identidade, e a certeza dentro das fronteiras nacionais ou 
étnicas" (LATOUR, 2020a, p. 41). Esse local-menos é uma resposta do povo traído pela globalização-menos, e por isso vemos o apoio ao novo nacionalismo e ao populismo. Efeitos desse local-menos podem ser identificados, como o Brexit $^{2}$ e a construção de um muro na fronteira entre os Estados Unidos e o México, por Donald Trump.

De fato, para Latour (2020a), a eleição de Donald Trump e sua política, na verdade, explicitam a necessidade da reformulação do mapa político: "[...] É como se Trump tivesse conseguido localizar um quarto atrator. [...] Pela primeira vez, o negacionismo climático define a orientação da vida pública de um país" (LATOUR, 2020a, p. 45). Enquanto, no esquema modernista, a noção de Local (atrator 1) e Global (atrator 2) são irreconciliáveis, Trump foge desse vetor combinando o pior dos dois mundos. A negação do aquecimento climático permite a Trump sustentar o ideal do American way of life como possível para todos os cidadãos. Por outro lado, ele infla as preocupações de defesa típica do local-menos. A gestão de Trump marca uma política em busca de um mundo irreal, inatingível e impossível: "[...] Não se trata de uma política da pósverdade, mas sim uma política da pós-política, ou seja, literalmente sem objeto, na medida em que ela rejeita o mundo em que reivindica habitar" (LATOUR, 2020a, p. 49). Em Why has critique run out of steam?, Latour (2004b) já relatara sua preocupação com o uso de argumentos dos Estudos das Ciências por políticos americanos para sustentar falsas controvérsias. A partir dos estudos sobre ciência e democracia de Latour comentados nesse texto, pode-se entender que esses tinham por objetivo fortalecer a democracia, uma vez que a libertariam do peso da Natureza absoluta. 0 uso de tais argumentos para defender elites obscurantistas e, portanto, inviabilizar o ideal da construção de um mundo comum subvertem o ideal original - o que parece ter sido recebido com bastante repulsa por Latour. Ver, por exemplo, sua entrevista recente (VRIEZE, 2017).

Dessa forma, o cenário contemporâneo é marcado, pelos possíveis movimentos, a três atratores totalmente inatingíveis: o mundo é pequeno demais para o Global, porém muito complexo para ser encaixotado nas fronteiras do Local, e o Fora-doMundo de Trump combina essas duas impossibilidades. Assim, por oposição ao atrator explicitado por Trump, precisamos nos mover em direção a um quarto atrator, o Terrestre (um novo ator político). Representamos o novo mapa político na figura 1 (B).

O argumento de Latour (2004b) é que nem o Global (mais ou menos) tampouco o Local (mais e menos) são polos viáveis: o mundo já se tornou complexo demais para caber dentro das fronteiras, porém não há mundo suficiente para o ideal do Global. E o fora-deste-mundo, mais do que qualquer outra coisa, não passa de uma grande ilusão.

A analogia que o autor faz é a de um avião que decolou de sua cidade origem em direção à cidade de destino. Ao se aproximar do destino, o piloto descobriu que o aeroporto de destino estava fechado e precisou voltar. Ao retornar para cidade de origem, o piloto descobriu que esse aeroporto também estava fechado. Ficamos presos no ar. É preciso, agora, aterrar. Ainda que não esteja perfeitamente entendido o que esse polo Terrestre significa, podemos reconhecê-lo por oposição ao Fora-desteMundo.

O fato de o polo terrestre estar fora do eixo local-global indica que precisamos de aliados que, originalmente, se propunham a defender um dos dois primeiros

${ }^{2} \mathrm{O}$ Reino Unido, que se expandiu pelo mundo, agora sai da Europa frente aos movimentos de imigrantes, povos sem terra em busca de um solo seguro. 
atratores. Precisamos pensar na defesa e proteção de nossas terras e de nossos povos, precisamos resistir ao avanço do global menos e olhar para os coletivos em sua inteireza e especificidade. Por outro lado, precisamos das ciências (e não da Ciência) para trabalharmos na direção da construção de um mundo e de uma Terra comum, habitável por todos os diferentes povos. Aterrar significa, nesse sentido, mobilizar coletivos sociedade-natureza em direção à Terra. Isso implica que, mais do que classes sociais, as articulações no período do Antropoceno nos exigem pensar em nossas classes geosociais. É preciso defender a terra. Ao mudar o problema ecológico da 'Natureza' para a terra, Latour (2020a) entende que se aumenta o poder de mobilizar as pessoas. Dizer que a Natureza está em risco é muito menos efetivo do que dizer a alguém que sua terra está por desabar. Essa segunda afirmação é muito mais visceral. E, portanto, é a nossa busca por poder aterrar de forma segura nos diferentes cantos do mesmo mundo que deve nos unir.

Nesse processo, não só precisamos passar da defesa da Natureza para defesa da terra, da Ciência para as ciências, mas também das ciências galileanas (ciências da natureza-universo) para as lovelockianas (ciências da natureza-processo). Não precisamos somente da ciência da natureza-universo para discutir os conflitos de território e os problemas da Zona Crítica (termo usado por Latour para designar a região abaixo da atmosfera terrestre). É importante ter clareza que sobre os problemas da Zona Crítica não somente os cientistas emitem seus pareceres, mas há uma rede de propostas concorrentes e problemas que são levantados por comunidades de diferentes tipos. Para que os conflitos sejam resolvidos é preciso mobilizar os conhecimentos científicos, mas é preciso dialogar com os diferentes atores. A solução para os conflitos de território não é e nem poderia ser independente de ações políticas.

É por isso que convém identificar entre os saberes positivos aqueles que tratam da Zona Crítica, de modo a não precisarmos nos ocupar do universo inteiro a cada vez que falamos de conflitos de território. [...] A situação é completamente diferente para as ciências da natureza-processo que se debruçam sobre a Zona Crítica. Nela, os pesquisadores se veem confrontados com conjuntos de saberes concorrentes que eles não têm o poder de desqualificar a priori. (LATOUR, 2020a, p. 96).

\section{Latour decidiu aterrar na Europa. E nós, onde vamos aterrar? No sul!}

A proposta de Latour (2020a) contraria a busca pelo global, sem com isso almejar o retorno ao local. Ainda assim, os conflitos geosociais e por terra nos obrigam a aterrar em uma terra específica, uma vez que os diferentes povos impactaram e impactam diferentemente o período do Antropoceno. Por isso, no último capítulo do livro, Latour se apresenta e, naturalmente, discute que ele irá aterrar na Europa. Mais do que isso, entretanto, Latour defende que será na Europa que se dará a construção de soluções para o Antropoceno: "[...] Sim, a Europa era perigosa quando se acreditava capaz de 'dominar' o mundo, mas vocês não acham que ela seria ainda mais perigosa se agora se encolhesse e tentasse, como se fosse um pequeno camundongo, esconder-se da história?" (LATOUR, 2020a, p. 122). Como europeu, Latour defende o protagonismo de sua própria terra: 
Em certa medida, é em seu território que podem convergir as três grandes perguntas de nosso tempo: como escapar da globalização-menos? Como suportar a reação do sistema terra às ações humanas? Como organizar para acolher os refugiados? Isso não quer dizer que os outros não farão essas coisas. Quer dizer apenas que a Europa, devido à sua história, deve dar o primeiro passo, já que foi a principal responsável. (LATOUR, 2020a, p. 124).

Uma vez que a proposta é territorializar as discussões, pensar no território europeu como o palco das soluções no Antropoceno, talvez, seja a única possibilidade que seu lugar privilegiado social e epistemicamente de europeu (QUIJANO, 2005) Ihe permite conceber. Isso não significa, como disse Alyne Costa (COSTA, 2020), no posfácio do livro Onde aterrar, que nós precisamos concordar com tal visão de Latour:

Não precisamos, é claro, concordar com a aposta de Latour. Há, decerto, razões de sobra para se indignar quando ele afirma, por exemplo, que o crime mais importante cometido pela Europa - a devastação ontológica e epistemológica empreendida em nome da civilização - é também um de seus trunfos. (COSTA, 2020, p. 155).

Latour, como europeu, decidiu aterrar na Europa. Nós, educadores e pesquisadores brasileiros, vamos aterrar onde? Nós propomos aterrar no Sul. Mas não somente o Sul geográfico do globo, mas o 'Sul' político, econômico e epistêmico do mundo (SANTOS; MENESES, 2009). Conforme aponta o sociólogo português Boaventura de Sousa Santos (SANTOS, 2019) o processo de colonização criou linhas abissais que dividem o mundo em norte (dos colonizadores) e sul (dos colonizados). No espaço urbano atual, na mesma cidade, uma mesma pessoa pode transitar pelo mundo do norte e do sul. Quando uma mulher, por exemplo, vê-se podendo reivindicar equidade salarial juridicamente, ela trava uma luta não-abissal (pois os mecanismos jurídicos do Estado de direito lhe são garantidos), mas quando essa mesma mulher, por exemplo, é vítima de violência doméstica e se encontra desamparada, seu drama é pós-abissal.

Uma das características do processo de colonização foi, justamente, a aniquilação das diferentes formas de ser e conhecer do Sul, o que Boaventura denomina de epistemicídio (SANTOS, 2019). Assim, posicionar-se no Sul, e com as Epistemologias do Sul, significa colocar-se a serviço da promoção da justiça social e cognitiva, visibilizando e legitimando as formas de ser e conhecer que o Norte tentou apagar. Aterrar no Sul é promover o mundo comum a partir do Sul, por meio do Sul e para o Sul (SANTOS; MENESES, 2009).

A partir dessa reflexão podemos, inclusive, conceber que o ideal de construção do mundo comum de que Latour fala, sempre foi a construção de um mundo comum para os habitantes do Norte e para a resolução dos conflitos não abissais. Para o Sul, a desigualdade social e a imigração sempre foram um problema, muito antes do período de pós-verdade e pós-política. Como discute Lélia Gonzalez (GONZALEZ, 1982), no período da ditadura militar, em que o processo de urbanização foi intensificado, testemunhou-se o crescimento e o inchamento das favelas, criando uma pobreza urbana cujas consequências se estendem e intensificam até hoje. Nesse sentido, se a Europa encara o problema da distribuição territorial na última década, no Brasil, a migração interna e a distribuição do espaço urbano e sua relação com a desigualdade 
social é um desafio antigo a ser superado, ainda que tenha se intensificado com a globalização, como discute Milton Santos (SANTOS, 2001, 2009).

Nesse cenário, enfrentar o problema territorial urbano demanda, também, reconhecer que, nas colônias, a escravidão deixou marcas profundas a serem reparadas. A noção de que o povo brasileiro é um povo cordial e que promoveu soluções pacíficas para suas tensões sociais é um mito que inviabiliza o reconhecimento do racismo estrutural (ALMEIDA, 2019) e violento que ainda rege diferentes dimensões da organização social brasileira (GONZALEZ, 2010). Assim, aterrar no Sul implica, também, se comprometer com uma proposição antirracista, o que pode ser traduzido em diferentes questões práticas (OLIVEIRA, 2020). Ainda, nesse mesmo sentido, aterrar no Sul significa trazer as reflexões de pensadores e pensadoras sulistas para interpretar e resolver os problemas do Antropoceno e não mais ficar refém das pautas e dos protagonistas da Ciência, da Filosofia e da Pedagogia do Norte.

Em síntese, aterrar no Sul significa, para nós, cuidar de Gaia a partir do Sul, se envolvendo na construção de um mundo comum, buscando soluções para os problemas da Zona Crítica, a partir do diálogo com as ciências, ou seja, construindo uma ecologia dos saberes (SANTOS, 2019). Isso deve ser feito valorizando a produção de conhecimento do sul, das ciências do sul, das lutas do sul e dos(das) pensadores(as) do sul. Ao mesmo tempo, precisamos investir no combate das desigualdades sociais e dos problemas de organização urbana a partir de um compromisso antirracista.

\section{Considerações finais: o que significa, para área de educação em ciências, aterrar e, mais especificamente, aterrar no sul?}

Podemos pensar que a educação e a educação científica também se organizam, usualmente, com relação aos polos Local e Global. Na área de Educação em Ciências, na qual se tem valorizado a discussão epistemológica e histórica há mais de três décadas (MATTHEWS, 1988), os posicionamentos podem ser orientados em um espectro entre relativista (e que, portanto, valoriza conhecimentos locais) e absolutista (e que, portanto, enfatiza uma ciência universal, global).

Como exemplo de educação científica global, podemos pensar nas propostas de ensino de conceitos, 'ciência pela ciência', pesquisas focadas em metodologias para ensinar Ciências melhor. Por outro lado, exemplos de educação científica locais podem ser encontrados em propostas que assumem a concepção multicultural (mas não multinatural), enfatizando a pluralidade de culturas, mas não de naturezas, concepção que compõe, por exemplo, uma linha temática no Encontro Nacional de Pesquisa em Educação em Ciências (ENPEC) ${ }^{3}$.

Deve-se mostrar que o paralelo entre a história que Latour conta e a história da educação em ciências parece factível. A noção de que a educação pública ofereceria uma formação científica universal a todos cidadãos, transformando o país em uma nação de primeiro mundo, portanto indo em direção ao global mais, na verdade, foi um projeto totalmente falido, que serviu apenas para reforçar as desigualdades já existentes (BOURDIEU; PASSERON, 2014), conduzindo ao global menos. Em resposta, viu-se uma intensificação de propostas localistas. Entretanto, a partir das discussões de Latour, pode-se imaginar que uma educação puramente local (que não dialogue 
com a complexidade do mundo 'modernizado') não dá conta de tratar dos problemas do Antropoceno, que mobilizam elementos das ciências ditas positivas.

O que precisamos fazer, então? Precisamos de uma educação terrestre, a qual, necessariamente precisa mobilizar atores dos dois atratores anteriores. Local e Global precisam mudar de rota em direção ao Terrestre. Pretendemos, esboçar alguns possíveis caminhos (não pretendemos aqui exaurir a proposta), que podem nos ajudar enquanto área a se posicionar político-epistemologicamente no Sul Terrestre:

a. Aterrar significa, para a área de Educação em Ciências, passar da Ciência da natureza-universo para as ciências da natureza-processo

A educação em ciências, usualmente, trata de 'objetos galileanos', ou seja, de uma Natureza única e inerte. As ciências que nos ajudarão a enfrentar os desafios do Antropoceno, entretanto, são as ciências da 'Zona Crítica', que se forjam no encontro de diferentes atores dos coletivos natureza-sociedade. Os problemas de que elas tratam são disputados por especialistas e não especialistas, emaranham-se em tensões e conflitos sociais, são atravessados pelas políticas e sensíveis ao discurso. Os temas da educação científica precisam adentrar os problemas da Zona Crítica em toda sua complexidade. Por tal motivo, o ensino de conceitos e processos científicos continua sendo um ponto central da educação no Antropoceno.

b. Aterrar no Sul significa, primeiramente, construir as pautas do Sul

Quais são os desafios que colocam a nossa terra prestes a desabar? Esses são os nossos objetos de discussão, e não a pauta imposta pelo Norte (AULER, 2018). A Amazônia está queimando mais do que usualmente? Por quê? O que podemos fazer? O isolamento 'horizontal' é eficiente no combate à pandemia? Como minimizar os efeitos sociais do isolamento? Como os padrões de consumo no nosso país estão alterando a nossa terra? Qual o papel das pessoas brancas na lógica das relações étnico-raciais no contexto brasileiro (NASCIMENTO, 2020)? Quais são as práticas e procedimentos que queremos no SUS? Observa-se que não se trata, aqui, de ensinar qual é a resposta correta para essas perguntas; mas de mobilizar conhecimentos para construir as respostas comuns. As ciências contribuem nesse processo, mas não o esgotam, visto que envolvem valores sociais, interesses, conflitos.

c. Aterrar no Sul significa, em segundo lugar, ol har para os problemas da zona crítica, também, a partir de marcos teóricos do Sul

Os problemas da Zona Crítica envolvem as ciências ditas positivas e, também, os conflitos sociais e políticos das diferentes dimensões da sociedade. Para se debruçar sobre esses problemas, marcos teóricos podem e devem ser mobilizados. Precisamos continuar discutindo, enquanto área, o que são as ciências, quais suas histórias e quais suas relações com a sociedade. Mas quais referenciais nos ajudam a pensar sobre essas questões? Apenas as ideias dos filósofos e sociólogos europeus e norte-americanos? Entendemos que não. Podemos olhar do Sul também a partir do Sul. Isso não significa abdicar de dialogar com o Norte. Propomos apenas que se ampliem as discussões a partir dos referenciais do Sul, mantendo o esforço para haver traduções interculturais. Nesse sentido, produções epistêmicas, como o conhecimento especializado tipicamente do Norte, podem ser trazidas no processo de ecologia dos saberes (SANTOS, 2019), desde que sejam mobilizadas no sentido de resolver as pautas do Sul. Ademais, parte do compromisso antirracista envolve visibilizar a produção de conhecimento de autores 
negros (PINHEIRO, 2019). Precisamos buscar os autores e as autoras que nos permitam entender o cenário contemporâneo em sua total complexidade.

Em especial, consideramos que as discussões antropológicas de Eduardo Viveiros de Castro (CASTRO, 1996, 2002), nas quais Latour, inclusive, se fundamenta ao trazer o conceito de multinaturalismo, trazem elementos importantes para se pensar a contemporaneidade. Em especial, do ponto de vista metodológico, Castro (2002) aponta para a necessidade de uma reflexão simétrica da Antropologia sobre a própria Antropologia, tratando de forma epistemologicamente horizontal a relação entre o 'antropólogo' e o 'nativo'. Tal proposição vai ao encontro das premissas teóricas defendidas por Latour e outros pesquisadores no campo da Teoria Ator-Rede na medida que privilegiam as falas dos diferentes atores envolvidos nas controvérsias sociotécnicas. Ademais, seus estudos sobre o perspectivismo ameríndio (CASTRO, 1996) permite-nos entender a profundidade e complexidade do pensamento multinaturalista discutido também por Latour e aponta para elementos importantes da sabedoria ecosófica, que foge ao pensamento hegemônico ocidental.

Dentro dessa mesma perspectiva multinaturalista, entendemos que a concepção e percepção ecológica, como as defendidas por Ailton Krenak (KRENAK, 2020a, 2020b), líder indígena que discute a necessidade da revisão de nossa percepção sobre a natureza e, por consequência, de nosso sistema econômico e organização social, podem contribuir para a refundação teórica que guiará nossa ação no Antropoceno. Da mesma forma, os conceitos de biointeração, confluência e transfluência de Antônio Bispo dos Santos (SANTOS, 2015), por exemplo, podem ser categorias importantes para analisar a sociedade e a ciência contemporânea, bem como suas discussões sobre culturas monoteístas e politeístas, que guardam paralelos com outra autora potente no cenário contemporâneo, Vandana Shiva (SHIVA, 2003).

d. A educação do Sul Terrestre precisa de uma Pedagogia do Sul para tratar da natureza-processo

Na Educação em Ciências busca-se ensinar algo pronto, ou já estabelecido. Mesmo em propostas progressistas, como os três momentos pedagógicos, os objetos da ciência não são colocados como objeto de questionamento e, frequentemente, falase da ciência galileana (BONFIM; COSTA; NASCIMENTO, 2018). Na educação científica do Sul Terrestre, por outro lado, os objetos de estudo não estão prontos, estão em processo de construção. Como diz Latour (2020a, p. 97): "[...] A Zona Crítica não é uma sala de aula; a relação com os pesquisadores é tudo menos puramente pedagógica". O problema aqui é, então, como transformar a sala de aula em um espaço propício para relações não 'puramente pedagógicas'. Latour deveria estar pensando em uma pedagogia conservadora ao falar isso. Provavelmente, ele não teve a oportunidade de conhecer uma pedagogia do Sul como a de Paulo Freire, como discutido por Santos (2019). De fato, a máxima freireana "[...] Ninguém educa ninguém, ninguém se educa a si mesmo, os homens se educam entre si, mediatizados pelo mundo" (FREIRE, 2013, p. 95) vai ao encontro da perspectiva metafísica, epistemológica e política que estamos propondo. A sala de aula é o espaço do encontro e da construção do mundo comum. O professor, nesse contexto, tem o papel de tradutor intercultural (SANTOS, 2019), mobilizando os conhecimentos das ciências ditas positivas para tensionar as discussões e a construção das soluções. 
A fim de oferecer exemplos de trabalhos recentes, no campo da educação, que trazem a integração entre uma perspectiva ecológica e decolonial, citamos a obra Educação ambiental desde el sur (KASSIADOU et al., 2018). Nesta coletânea são apresentados diferentes estudos conceituais e empíricos que aproximam as perspectivas teóricas supracitadas. Em especial, consideramos o conceito trazido pelos autores de Desobediência epistêmica (MIGNOLO, 2008), um tema central a ser debatido em favor da construção de uma verdadeira ecologia dos saberes. Ademais, em trabalho recente apresentamos algumas reflexões e proposições para repensarmos o papel da educação científica no cenário contemporâneo (LIMA; NASCIMENTO, 2019).

Entendemos que os quatro pontos apresentados iniciam (e não finalizam) a construção de um programa de pesquisa e ação para que a educação em ciências possa aterrar no Sul. Tal proposta político-epistemológica é, portanto, uma defesa do resgate da vontade de se construir um mundo comum, habitável e respirável por todos. Para isso, entendemos que as divergências devem ser traduzidas em ganho de complexidade, para que possamos, juntos, enquanto área de produção de conhecimento, produzir também um coletivo sociedade-natureza mais justo, saudável e democrático.

\section{Referências}

ALMEIDA, S. Racismo estrutural. São Paulo: Polen, 2019.

ARENDT, H. A condição humana. Rio de Janeiro: Forense Universtaria, 2007.

AULER, D. Cuidado! um cavalo viciado tende a voltar para o mesmo lugar. Curitiba: Appris, 2018.

BONFIM, D. D. S.; COSTA, P. C. F.; NASCIMENTO, W. J. A abordagem dos três momentos pedagógicos no estudo de velocidade escalar média. Experiências em Ensino de Ciências, Cuiabá, v. 13, n. 1, p. 187-197, 2018. Disponível em: https://cutt.ly/xQWmhJ6. Acesso em: 30 jul. 2021.

BOURDIEU, P.; PASSERON, J.-C. Reprodução: elementos para uma teoria do sistema de ensino. 7. ed. Petrópolis: Vozes, 2014.

BUNGE, M. Buscar la filosofía en las ciencias sociales. Madrid: Siglo XXI, 1999.

CASTRO, E. V. O nativo relativo. Mana, Rio de Janeiro, v. 8, n. 1, p. 113-138, 2002. DOI: https://doi. org/dk4r4j.

CÉNAT, J. M.; DALEXIS, R. D.; KOKOU-KPOLOU, C.; MUKUNZI, J. N.; ROUSSEAU, C. Social inequalities and collateral damages of the COVID-19 pandemic: when basic needs challenge mental health care. International Journal of Public Health, Basel, v. 65, n. 6, p. 717-718, 2020. DOI: https://doi.org/ gg4rnz.

COLLINS, H. M.; EVANS, R. The third wave of science studies: studies of expertise and experience. Social Studies of Science, London, v. 32, n. 2, p. 235-296, 2002. DOI: https://doi.org/cbrv4z.

COSTA, A. Aqui quem fala é da Terra. In: LATOUR, B. Onde aterrar?: como se posicionar politicamente no Antropoceno. Rio de Janeiro: Bazar do Tempo, 2020. p. 115.

COSTA, A. C. Guerra e paz no antropoceno: uma análise da crise ecológica segundo a obra de Bruno Latour. Rio de Janeiro: Autografia, 2017.

COUTINHO, F. A.; SILVA, F. A. R. Sequências didáticas: propostas, discussões e reflexões teóricometodológicas. Belo Horizonte: UFMG: FAE, 2016. 
DRESSLER, F. C. S.; SILVA, F. A. R.; SATO, D. S. A teoria ator-rede em uma sequência didática para discussão do tema ecossistemas e suas transformações. Revista Brasileira de Educação em Ciências e Educação Matemática, Cascavel, v. 4, n. 2, p. 165-188, 2020. DOI: https://doi.org/gqb9.

FARIA, S. E.; COUTINHO, A. F. Educação científica em ação: a cartografia das controvérsias como prática de cidadania técnico-científica. Cadernos de Pesquisa, São Luís, MA, v. 22, n. 3, p. 133-147, 2015. DOI: https://doi.org/gqcc.

FREIRE, P. Pedagogia do oprimido. Rio de Janeiro: Paz e Terra, 2013.

GONZALEZ, L. O movimento negro na última década. In: GONZALEZ, L.; HASENBALG, C. Lugar de negro. Rio de Janeiro: Marco Zero, 1982. p. 9-66.

GONZALEZ, L. Primavera para as rosas negras. São Paulo: Selo Negro Edições, 2010.

HARMAN, G. Prince of networks: Bruno Latour and metaphysics. Melbourne: re.press, 2009.

KASSIADOU, A.; SÁNCHEZ, C.; CAMARGO, D. R.; STORTTI, M. A.; COSTA, R. N. Educação ambiental desde el sur. Macaé: Ed. Nupem, 2018. Disponível em: https://cutt.ly/fQWmKoN. Acesso em: 31 jul. 2021.

KRENAK, A. Ideias para adiar o fim do mundo. São Paulo: Companhia das Letras, 2020a.

KRENAK, A. A vida não é útil. São Paulo: Companhia das Letras, $2020 \mathrm{~b}$.

LATOUR, B. A esperança de Pandora: ensaios sobre a realidade dos estudos das ciências. São Paulo: Ed. da Unesp, 2017.

LATOUR, B. Diante de Gaia: oito conferências sobre a natureza no antropoceno. São Paulo: Editora Ubu, 2020b.

LATOUR, B. Jamais fomos modernos. São Paulo: Editora 34, 2013.

LATOUR, B. Onde aterrar?: como se orientar politicamente no antropoceno? Rio de Janeiro: Bazar do Tempo, 2020a.

LATOUR, B. Políticas da natureza: como fazer ciência na democracia. Bauru: EDUSC, 2004a.

LATOUR, B. Reassembling the social: an introduction to actor network theory. Oxford: Oxford University Press, 2005.

LATOUR, B. Why has critique run out of steam?: from matters of fact to matters of concern. Critical Inquiry, Chicago, v. 30, n. 2, p. 225-248, 2004b.

LATOUR, B.; WOOLGAR, S. A vida de laboratório: a produção dos fatos científicos. Rio de Janeiro: Relume Dumará, 1997.

LIMA, N. W.; VAZATA, P. A. V.; OSTERMANN, F.; CAVALCANTI, C. J. H.; MORAES, A. G. Educação em ciências nos tempos de pós-verdade: reflexões metafísicas a partir dos estudos das ciências de Bruno Latour. Revista Brasileira de Pesquisa em Educação em Ciências, Belo Horizonte, v. 19, p.155189, 2019. DOI: https://doi.org/gpq7.

LIMA, N. W.; NASCIMENTO, M. M. Nos becos da episteme: caminhos confluentes para uma contra colonização didática em meio à crise da verdade. Caderno Brasileiro de Ensino de Física, Florianópolis, v. 36, n. 3, p. 589-598, 2019. DOI: https://doi.org/gqcf.

MATTHEWS, M. R. A role for history and philosophy in science teaching. Educational Philosophy and Theory, Hoboken, v. 20, n. 2, p. 67-81, 1988. DOI: https://doi.org/d97w77.

MBEMBE, A. Le droit universal à la respiration. AOC, Paris, 6 avr. 2020. Disponível em: https://cutt. ly/6QWQyol. Acesso em: 11 dez. 2020. 
MIGNOLO, W. D. Desobediência epistêmica: a opção descolonial e o significado de identidade em política. Cadernos de Letras da UFF, Niterói, n. 34, p. 287-324, 2008.

NASCIMENTO, M. M. Os privilégios da branquitude e a reprodução de desigualdades sociais na educação brasileira. Educação, Cultura e Sociedade, Sinop, v. 10, n. 2, p. 21-33, 2020. Disponível em: https://lume.ufrgs.br/handle/10183/218637. Acesso em: 30 jul. 2021.

OLIVEIRA, L. F. Opção decolonial e antirracismo na educação em tempos neofascistas. Revista da $A B P N$, Guarulhos, v. 12, n. 32, p. 11-29, 2020. DOI: https://doi.org/gqcj.

PINHEIRO, B. C. S. Educação em ciências na escola democrática e as relações étnico-raciais. Revista Brasileira de Pesquisa em Educação em Ciências, Belo Horizonte, p. 329-344, 2019. DOI: https://doi.org/gqck.

QUIJANO, A. Colonialidade do poder, eurocentrismo e América Latina. In: LANDER, E. (org.). A colonialidade do saber: eurocentrismo e ciências sociais. Buenos Aires: CLACSO, 2005. p. 345-392.

RODRIGUES, V. P.; OLIVEIRA, I. C.; CHAVES, G. L. D.; AQUINO, E. L. C.; VIEGAS, C. V. Pandemic responses in vulnerable communities: a simulation-oriented approach. Revista de Administração Pública, Rio de Janeiro, v. 54, n. 4, p. 1111-1122, 2020. DOI: https://doi.org/gp4b.

SANTOS, A. B. Colonização quilombos: modos e significados. Brasília: INCTI: UnB, 2015.

SANTOS, B. S. A cruel pedagogia do vírus. Coimbra: Almedina, 2020.

SANTOS, B. S. O fim do império cognitivo: a afirmação das epistemologias do sul. Belo Horizonte: Autêntica, 2019.

SANTOS, B. S.; MENESES, M. P. Epistemologias do sul. Coimbra: Almedina, 2009.

SANTOS, M. Pobreza urbana. São Paulo: Edusp, 2009.

SANTOS, M. Por uma outra globalização: do pensamento único à consciência universal. 6. ed. Rio de Janeiro: Record, 2001.

SHIVA, V. Monoculturas da mente: perspectivas de biodiversidade e da biotecnologia. São Paulo: Gaia, 2003.

SOKAL, A.; BRICMONT, J. Imposturas intelectuais: o abuso da ciência pelos filósofos pós-modernos. 4. ed. Rio de Janeiro: Record, 2010.

STENGERS, I. Réactiver le sens commun: lecture de Whitehead en temps de débâcle. Paris: La Découverte, 2020.

VRIEZE, J. Bruno Latour, a veteran of the 'science wars', has a new mission. Science, New York, v. 358, n. 6360, p. 159, 13 Oct. 2017. DOI: https://doi.org/gc3gg7.

WHITEHEAD, A. N. Process and reality: an essay in cosmology. New York: The Free Press, 1978. 